
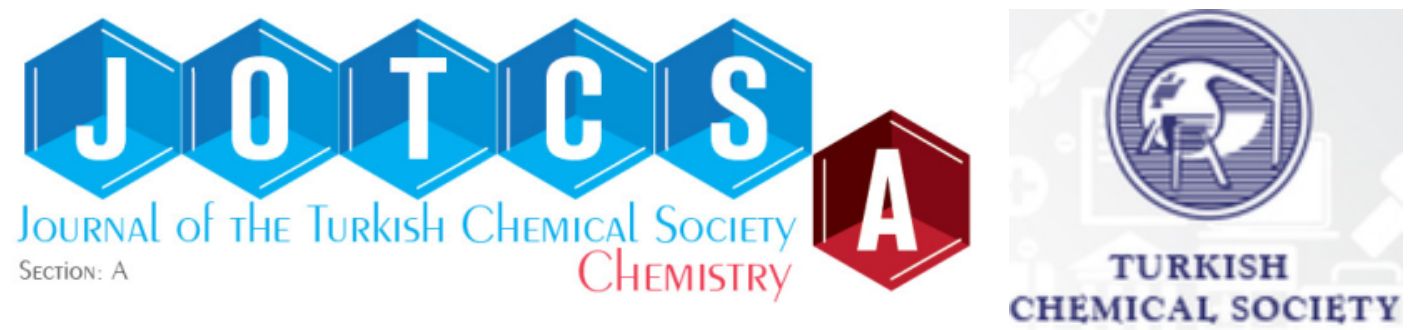

\title{
Ricinus communis Seed Oils as a Source of Biodiesel; A Renewable Form of Future Energy
}

\author{
Hadush Gebrehiwot $^{1 *}$ (D) and Demis Zelelew ${ }^{2}$ \\ ${ }^{1}$ Wachemo University, Department of Chemistry, Hossana, P.O. Box 667, Ethiopia \\ ${ }^{2}$ Adama Science and Technology University, Department of Applied Chemistry, Adama, P.O. Box: 1888, \\ Ethiopia
}

\begin{abstract}
Diminishing supply and environmental pollution of fossil fuels are the vital factors leading to the search of alternative sources of energy like biodiesel. Biodiesel is one of the eco-friendly substitutes of energy which is mainly utilized in diesel engines. Ricinus communis (castor plant), which belongs to the family Euphorbiaceae yields an oil rich beans and plays important role in the production of biodiesel. Recently, the demand of castor oil and its products has been raised in the world market due to its versatility to use and simplicity to produce. Therefore, this study investigates the extraction of castor oil and its conversion in to biodiesel via alkali catalyzed transesterification. The seed oil of the plant was extracted using Soxhlet apparatus and the quality of the biodiesel was examined using the standard procedures of American standards for testing methods. Furthermore, the chemical composition of the extracted oil was examined using GC-MS. The seed oil was liquid at room temperature $\left(25^{\circ} \mathrm{C}\right)$, golden yellow in color with a nutty odor. The extraction processes yielded $324 \mathrm{~g}(9.25 \% \mathrm{w} / \mathrm{w})$ and $78 \%$ of oil and biodiesel respectively. The density $(0.86 \mathrm{~g} / \mathrm{mL})$, viscosity $\left(5.42 \mathrm{~mm}^{2} \mathrm{~s}^{-1}\right)$, flash point $\left(87^{\circ} \mathrm{C}\right)$, acid value $(0.35 \mathrm{mg} \mathrm{KOH} / \mathrm{g})$, water content $(0.80 \%)$, iodine value $(108.60)$, and cetane number (58.00) were reported in this study and showed a good agreement with the standards of biodiesel. GC-MS analysis of the seed oil also showed the presence of 10 different fatty acids (9-Octadecenoic acid, 12-hydroxy-, methyl ester, $[R-(Z)]$ took the highest composition) which plays significant role for the production of methyl esters. So, the study can assure that castor oil can be used for commercial production of biodiesel at cost effective scales.
\end{abstract}

Keywords: Biodiesel, GC-MS, Renewable energy, Ricinus communis, Transesterification

Submitted: November 12, 2021. Accepted: February 12, 2022.

Cite this: Hadush G, Demis Z. Ricinus communis Seed oils as a Source of Biodiesel; A Renewable Form of Future Energy. JOTCSA. 2022;9(2):339-54.

DOI: https://doi.org/10.18596/jotcsa.1019969.

*Corresponding Author. E-mail: hadushgebrehiwot@yahoo.com.

\section{INTRODUCTION}

Today, one of the great problems of humanity is its dependence on non-renewable forms of energy which have a nature of depletion, economic disturbances, and negative environmental impacts (1). Currently, fossil fuels cover most of the energy used in the world. They are broadly used for cooking, generation of electricity, transportation, to heat environments, etc. However, a concern has been generated, that leads to the search and the study of new sources for the production of biofuels.
The challenge is to ensure that those energy sources are gradually replacing the fossil fuels (2).

The diminution of natural oil which leads to high oil price and emission of greenhouse gases make renewable energy sources more attractive. One of the best ways to reduce our dependence on petroleum reserves is to develop renewable fuels such as biodiesel (3). Recently, biodiesel is evolving to be one of the most employed biofuels for partial replacement of petroleum based diesel fuel (4). The demand and consumption of petroleum products are 
increasing from time to time due to the increase in population, living standards, and urbanization. The use of diesel machineries has been banned in some cities of the world like in India for serious problems of air pollution due to higher emissions of poisonous gasses. Global warming, depletion of ozone layer, and acidic rain are some of the consequences of the toxic gases from petroleum fuels (5).

Methyl ester fatty acid (biodiesel) is one of the key solutions of the future threats of petroleum fuels because of its renewability and friendship to the environmental. Surveys conducted by different researchers revealed that currently more than 95 percent of biodiesel is produced from edible oil sources $(6,7)$ (Scheme 1 ). Use of alternative nonedible oil sources such as castor oil, jatropha oil, algae oil, karanja (Pongamia pinnata), tobacco (Nicotiana tabacum), rubber plant (Hevea brasiliensis), waste cooking oil etc. are gaining increasing attention and are broadly under examination $(8,9)$.

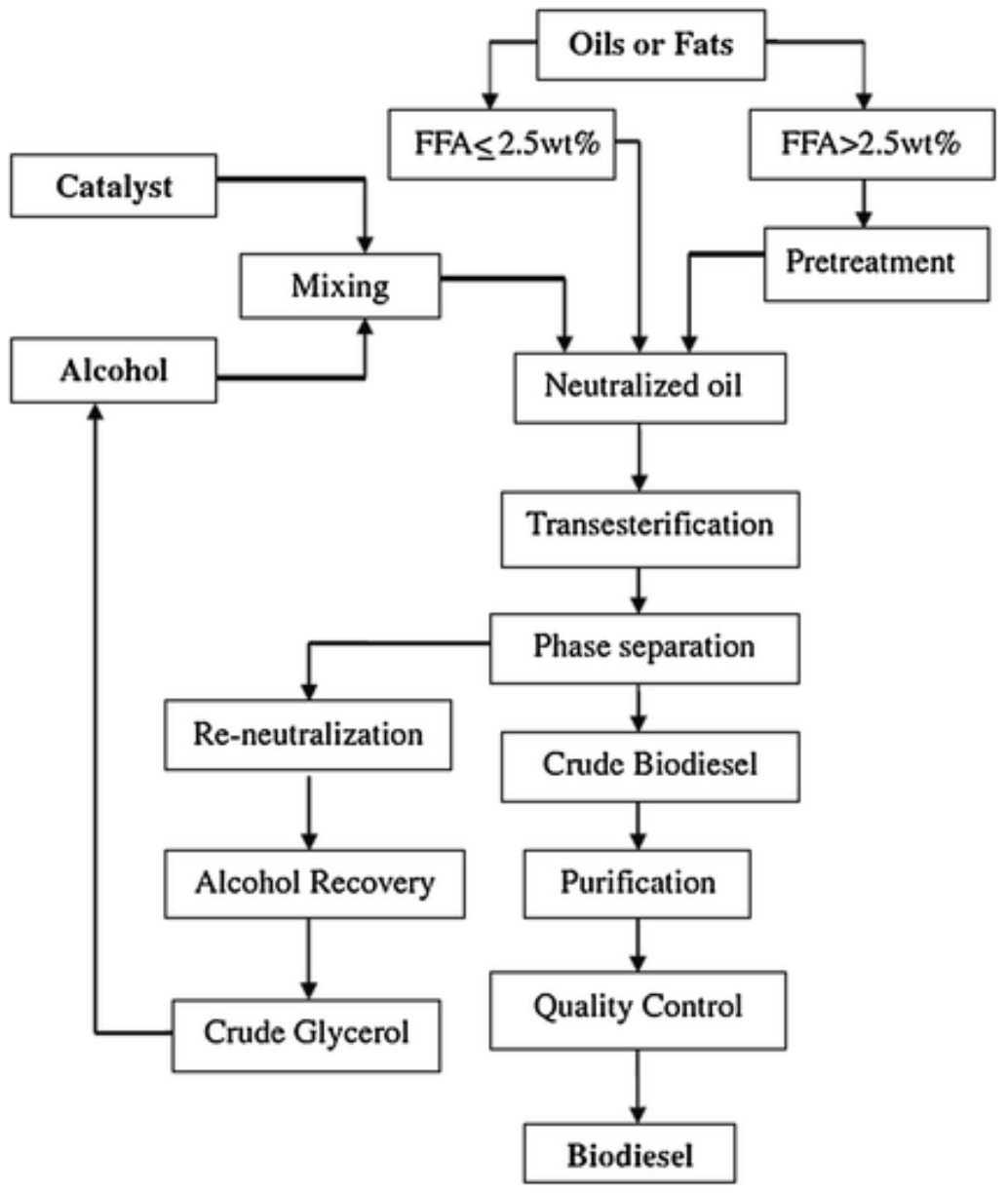

Scheme 1: Production of biodiesel via transesterification process (10).

Ricinus communis (castor plant) belongs to the family Euphorbiaceae and grows in both domestic and wild climatic conditions (4, 11, 12). The plant produces castor beans that are rich of castor oil (up to $50 \%$ oil by weight). The oil can easily be produced from the seeds of the plant and is used in many sectors such as chemical industry, agriculture, medicine and other technologies (13). Nowadays, the demand for castor oil and its products has been on the steady increase in the world market due to its low costs, eco-friendliness, non-competition with food, renewable nature and biodegradability (2). The chemistry of $R$. communis oil is mainly aligned on ricinoleic acid which takes place in high content in the seed oil of the plant and possess three functional groups. These functional groups are essential towards the versatility of the oil for the production of many castor oil based products (14, 15). The presence of carboxylic functional group, for example, can lead to a wide range of esterification products. Whereas, the presence of hydroxyl functional group, can be acetylated, alkoxylated, or removed by dehydration to increase the unsaturation of the oil (16-18).

R. communis (Figure 1 ) is locally called Gulo (Amharic name) and is one of the biodiesel feed stocks. The beans contain a toxin that makes the oil and cake inedible. It grows very well on marginal land, it is drought- and pest-resistant and is one of the highest viscosities among vegetable oils (19, $20)$. The oil extracted from the seed of castor plant 
( $R$. communis) has stimulated some interests such as production of biodiesel. $R$. communis beans are non-edible biodiesel raw materials to substitute the consumption of fossil fuels. Furthermore, they are widely available and has no any other commercial purpose, has high oil content, grows in marginal land and has a resistance for variable climatic and soil conditions (21).
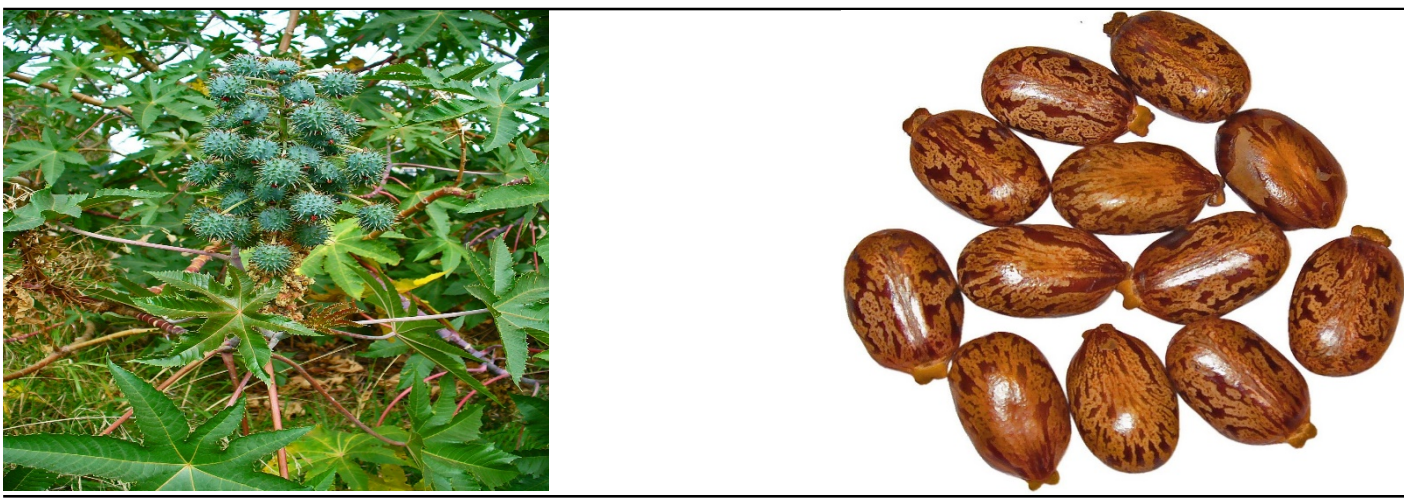

Figure 1: Castor plant (left) and castor seeds (right).

Ethiopia is one of the most suitable nations in Africa for tapping renewable sources of energy because of its location and natural wealth. The country has been looking at enhancing its energy capacity, especially over the past twenty years (9). The government recently issued biofuel strategies to encourage domestic biofuel production, with an objective of reducing the dependence on high-cost fossil oil. The plant possess high oil content (45\%$55 \%$ ) relative to other plants in the country and got a great attention by stakeholders (22) (Table 1).

Table 1: Comparison of the most common biodiesel feed stocks.

\begin{tabular}{|c|c|c|c|c|}
\hline Seed type & Oil content (\%) & Advantage & Disadvantage & References \\
\hline Castor bean & $45-55$ & $\begin{array}{l}\text { High flash point, high } \\
\text { pour point, high } \\
\text { cloud point, non- } \\
\text { edible, miscible with } \\
\text { alcohol }\end{array}$ & $\begin{array}{l}\text { High viscosity, low } \\
\text { cetane number }\end{array}$ & $(23-29)$ \\
\hline Rapeseed & $38-46$ & $\begin{array}{l}\text { Low cloud point, high } \\
\text { flash point }\end{array}$ & $\begin{array}{l}\text { High NOx emissions } \\
\text { in most experiments }\end{array}$ & $(24,25,27,29,30)$ \\
\hline Mustard & $28-32$ & $\begin{array}{l}\text { Cheap feed stock, } \\
\text { high cetane number }\end{array}$ & $\begin{array}{l}\text { High cloud point, low } \\
\text { heating value, high } \\
\text { viscosity }\end{array}$ & $(24,27,29,31-34)$ \\
\hline Palm & $18-40$ & $\begin{array}{l}\text { High flash point, } \\
\text { cheap feed stock }\end{array}$ & $\begin{array}{l}\text { Edible, high cloud } \\
\text { point }\end{array}$ & $(24,25,27-29,35)$ \\
\hline Sunflower & $25-35$ & Low viscosity & Long term cultivation & $(24,25,27-29,35)$ \\
\hline Soybean & $15-20$ & $\begin{array}{l}\text { High thermal } \\
\text { stability, low } \\
\text { viscosity }\end{array}$ & $\begin{array}{c}\text { High acid value, long } \\
\text { term cultivation, } \\
\text { edible, }\end{array}$ & $(24,25,27-29)$ \\
\hline
\end{tabular}

Biodiesel should be investigated for some important parameters to ensure its quality before it is used in different kinds of fuel machineries (36). Biodiesel density (the measure of the degree of combustion and atomization), viscosity (the property to resist the relative movement tendency), flash point (the minimum temperature at which the fuel will ignite), acid value (to quantify the acid moieties in the biodiesel), iodine value (the measure of the total unsaturation of fatty acids), water content and cetane number (the measure of ignition quality of biodiesel) are some substantial parameters of biodiesel that should be taken in to consideration before application (37-42).

Transesterification is the displacement of alcohol from an ester by another in a process similar to hydrolysis, except alcohol is used instead of water. This process has been widely used to reduce the high viscosity of triglycerides. A catalyst is usually used to improve the reaction rate and yield (Scheme 2 ). Excess alcohol is used to shift the equilibrium toward the product because of reversible nature of the reaction $(16,37,43)$. 
<smiles>[R]C(=O)OCC(COC([R])=O)OC([R])=O</smiles>

Triglyceride<smiles>[R]C(=O)OC</smiles>

Methyl ester

Scheme 2: Transesterification process.

The production of biodiesel in Africa in general and in Ethiopia in particular is at its infant stage and has yet to mature. That is because much of the struggles in Africa so far have fixated on nurturing the feedstock market. Although many works have been performed on the transesterification of nonedible oils of many seed oils; few studies have been done on the optimization, oil characterization, and fuel analysis of the non-edible oil seeds particularly $R$. communis. So, the present work aimed to study the seed oil of $R$. communis as a source of future renewable energy. The study has a remarkable finding on the important aspects of the seed oil of $R$. communis as a feed stock for biodiesel production at global perspectives in general and in Ethiopia in particular.

\section{EXPERIMENTAL}

\section{Plant Materials}

The plant materials were collected from a farm land around Abiy Adi, central province, $95 \mathrm{~km}$ from the capital of Tigray, Ethiopia. After collection the seeds were allowed to air dry, washed first with tap water and then with distilled water. The air dried seeds were ground in to coarse powder using an electric blender (Panasonic, Japan). Finally, the sample materials were sealed in a polyethylene bag to prevent from certain environmental factors.

\section{General Experimental Procedures}

The seed oil of $R$. communis was extracted using Soxhlet extractor (Lab Tech Grey Soxhlet Apparatus, BST/SXM-1, India). The concentration/drying process of the oil was achieved using rotary evaporator (RV 3V, IKA, Germany). The biodiesel was produced by alkali-catalyzed transesterification method on a hot plate. The chemical composition of the seed oil was determined using Shimadzu QP2010 GC-MS (Shimadzu, Kyoto, Japan). Furthermore, the physico-chemical parameters of the biodiesel were tested and the instruments used are described under the procedure of each parameter.

\section{Extraction Methods}

Soxhlet extraction

About $3.5 \mathrm{~kg}$ of the powdered seeds of the plant were subjected to Soxhlet extraction (chemical method). $250 \mathrm{~mL}$ of $\mathrm{n}$-hexane was poured into a round-bottomed flask and $100 \mathrm{~g}$ of the sample was placed in the thimble and extracted using Soxhlet extractor at $60{ }^{\circ} \mathrm{C}$ for $3 \mathrm{hrs}$. Distinct layers of oil and n-hexane appeared in the round-bottomed flask. The resulting mixture containing oil was concentrated using a rotary evaporator (RV 3V, IKA, Germany) to evaporate the solvent and weighed again to determine the amount of oil extracted. This procedure was repeated many times to generate sufficient oil (44).

\section{Transesterification}

An alkali-catalyzed transesterificaton method was used to produce the biodiesel. The crude oil was filtered by Whatman filter paper No 1 and the filtered oil was heated up to $125^{\circ} \mathrm{C}$ on hot plate to decompose triglycerides into monoglycerides and diglycerides. Transesterification of $324 \mathrm{~mL}$ of oil was done for the production of methyl esters by using different alkaline catalysts (45).

$3.5 \mathrm{~g}$ of $\mathrm{NaOH}$ was mixed with methanol $(100 \mathrm{~mL})$ to make alkali methoxide which was used as a catalyst in the reaction. The prepared methoxide was added to $324 \mathrm{~mL}$ of oil at $60^{\circ} \mathrm{C}$ and stirred for 40 minutes at $600 \mathrm{rpm}$. After stirring the reaction mixture was kept overnight at room temperature to settle down distinct layers i.e. upper layer soap, middle layer of FAME (fatty acid methyl esters) and the bottom dense layer of glycerin. These layers were then separated through a glass separating funnel. The biodiesel was washed with ordinary tap water in order to remove impurities and suspended particles. Four washings were performed for complete clearance of the biodiesel. Few drops of acetic acid were also added and the residual water was eliminated by treatment with anhydrous sodium sulfate $\left(\mathrm{Na}_{2} \mathrm{SO}_{4}\right)$ followed by filtration $(44,45)$. 


\section{Determination of Free Fatty Acid Number}

The contents of free fatty acid were determined by aqueous acid-base titration method. Two types of titration i.e. blank titration and sample titration were performed. In case of blank titration, $1.4 \mathrm{~g} \mathrm{KOH}$ were dissolved in $1000 \mathrm{~mL}$ of distilled water to prepare $0.025 \mathrm{M} \mathrm{KOH}$ solution and this solution were poured into a burette. $10 \mathrm{~mL}$ of isopropyl alcohol and 3 drops of phenolphthalein were mixed in an Erlenmeyer flask and titrated against $0.025 \mathrm{M}$ $\mathrm{KOH}$ from the burette until the color of the solution became pink. The volume of $\mathrm{KOH}$ used was recorded and this process was repeated three times to calculate the mean volume of $\mathrm{KOH}$ used for blank titration. While in the sample titration, $9 \mathrm{~mL}$ isopropyl alcohol, $1 \mathrm{~mL}$ of $R$. communis oil and 3 drops of phenolphthalein were taken into an Erlenmeyer flask and titrated against $0.025 \mathrm{M} \mathrm{KOH}$ from the burette until the end point. The volume of $\mathrm{KOH}$ used was recorded and three readings were taken by repeating the same experiment to calculate the mean volume of $\mathrm{KOH}$ used to titrate the sample (44). Finally, the value of acid number was calculated using (Equation 1).

$$
\text { Acid number }=\frac{(A-B) \times C}{D}
$$

Where, $A=$ Volume used in sample (actual titration),

$\mathrm{B}=$ Volume used in blank titration,

$\mathrm{C}=$ Mass of catalyst in $\mathrm{g} / \mathrm{L}$,

$\mathrm{D}=$ Volume of oil used.

\section{Physicochemical Characterization of the Biodiesel}

Iodine value

The iodine value was determined through the method described by Jessinta, et al., 2014 (46) with slight modifications. $0.1 \mathrm{~g}$ of the biodiesel was measured in to an Erlenmeyer flask and $20.0 \mathrm{~mL}$ of carbon tetrachloride was added and the flask was sealed until complete dissolution. 25.0 mL of Hanus' solution (Iodine monobromide in glacial acetic acid, $\mathrm{C}=0.1 \mathrm{~mol} / \mathrm{L}$ ) was added into the previous solution, sealed and shaken for one minute. The sealed solution was left in a dark room (about $20^{\circ} \mathrm{C}$ ) for 30 minutes. Meanwhile $10.0 \mathrm{~mL}$ of $15 \%$ potassium iodide and $100 \mathrm{~mL}$ of water were added, sealed and shaken for 30 seconds. Finally the resulted solution was titrated with $0.1 \mathrm{~mol} / \mathrm{L}$ sodium thiosulfate and the iodine value was calculated as follows (Equation 2) (46).

$$
\begin{aligned}
& \text { Iodine value }=\frac{(B L 1-E P 1) \times T F \times C 1 \times K 1}{S} \\
& \text { Where, EP1 = titration volume }(\mathrm{mL}), \\
& \mathrm{BL} 1=\text { Blank level }(47.074 \mathrm{~mL}), \\
& \mathrm{TF}=\text { Factor of titrant }(1.006), \\
& \mathrm{C} 1=\text { Concentration conversion coefficient (1.269), } \\
& \mathrm{K} 1=\text { Unit conversion coefficient }(1), \\
& \mathrm{S}=\text { Sample size }(\mathrm{g}) .
\end{aligned}
$$

\section{Biodiesel density}

The density of the biodiesel was measured using a digital hydrometer (DA-130N, India). $20 \mathrm{~mL}$ of biodiesel sample was added in a graduate beaker, measuring room temperature using a thermometer. The hydrometer was dropped inside the beaker with biodiesel until the hydrometer stops and the density was read $(25,47,48)$.

\section{Cetane number}

The Cetane number (CN) of the biodiesel was measured by using ignition quality tester (Advanced Engine Technology, India). This is a method that measures the time delay between the start of fuel injection and the start of significant combustion through auto-ignition of a pre-measured amount of diesel in a constant volume chamber. The time delay is used with a formula to calculate the Derived Cetane Number (DCN) which correlates to the D613 cetane engine $(48,49)$.

\section{Flash point}

The flash point of the biodiesel was measured by Pensky-Martens flash point tester (PMA 500, India). The flash point cup was filled with a biodiesel and was heated in the apparatus. It reads a point after the thermometer was put. The temperature at which the vapor reacted with the atmospheric air and gets ignited was recorded (50).

\section{Viscosity}

The viscosity of the biodiesel was calculated using Bitumen Dynamic Viscosity Apparatus (GD-0620A, China). The capillary viscometer was filled with the biodiesel. The sucker or filler of the viscometer was fixed to the upper part of the tube and then pumped till the fluid passes to the mouth of the tube. The time taken as the biodiesel moves down till it gets to the lower tube of the viscometer was recorded and multiplied by 0.01126 (51). 
Water content

The water content (WC) was determined by the standard oven method, in which a sample is weighed, dried in an oven at $105^{\circ} \mathrm{C}$ for normally 12 hours and then weighed again (21) (Equation 3 ).

$$
\text { Water content }(\%)=\frac{\text { Mass of water }}{\text { mass of biodiesel }} \times 100
$$

\section{Acid value}

The acid value was calculated by direct titration methods of oil against standard $\mathrm{KOH}$ in an alcoholic medium according to the method described by Jessinta et al., 2014 (46) with slight modifications. $0.5 \mathrm{~g}$ of oil was weighed into a $250 \mathrm{~mL}$ Erlenmeyer flask and $50 \mathrm{~mL}$ of freshly neutralized hot ethyl alcohol and $1 \mathrm{~mL}$ of phenolphthalein indicator solution were added. The mixtures were boiled up to 5 minutes and titrated against standardized potassium hydroxide $(0.24 \mathrm{M})$. The acid value was then calculated using (Equation 4).

$$
\text { Acid Value }=\frac{[56.1][\text { titration of standard }(m L)][\text { molarity of standard }(M)]}{\text { weight of sample }(g)}
$$

\section{GC-MS Analysis of $R$. communis Seed Oil}

The extracted oil was subjected to GC-MS analysis for its components using a Shimadzu QP2010 gas chromatograph coupled with mass spectroscopy detector (Shimadzu, Kyoto, Japan). A temperature range of $70{ }^{\circ} \mathrm{C}$ to $280{ }^{\circ} \mathrm{C}$ was set at and a carrier gas (helium) was used. The injection volume was set to be $2 \mu \mathrm{L}$ at $250{ }^{\circ} \mathrm{C}$ with a flow rate of 1.80 $\mathrm{mL} / \mathrm{min}$. ACQ scanner having 30-700 amu range at speed of 1478 was operated for mass spectroscopy (Shimadzu, Kyoto, Japan). NIST05 mass spectral library (NIST, 2012) was used as a standard for comparison of spectral data obtained after the analysis (52).

\section{Data Analysis}

Results were calculated using MS Excel (2013) and the physicochemical parameters of the biodiesel were determined using the standard procedures and compared with the standards of biodiesel (ASTM D 6751) and petrol diesel (ASTM D975) fuels described by ASTM. The compounds from GC-MS

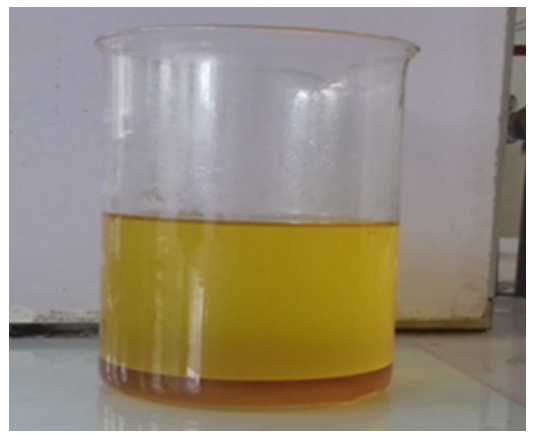

Left, glycerin and biodiesel layers were identified by means of their retention times, mass spectral fragmentation patterns and by comparing their mass spectra with the NIST 2012 library of mass spectra.

\section{RESULTS AND DISCUSSION}

\section{Percentage Yield}

The extracted oil was liquid at room temperature $\left(25^{\circ} \mathrm{C}\right)$, golden yellow in color with a nutty odor. An alkali catalyzed transesterificaton technique was used for the production of the biodiesel and results revealed that three distinct layers (upper layer soap, middle layer biodiesel, and bottom layer glycerol) were formed after keeping the reaction mixtures overnight at room temperature. The extraction processes yielded $324 \mathrm{~g}(9.25 \% \mathrm{w} / \mathrm{w})$ and $78 \%$ of seed oil and biodiesel respectively (figure 2 ). The harvesting time, method of extraction, growing region, damage caused by pests and maturity of the seeds were the main factors presented for the small yield of the seed oils.

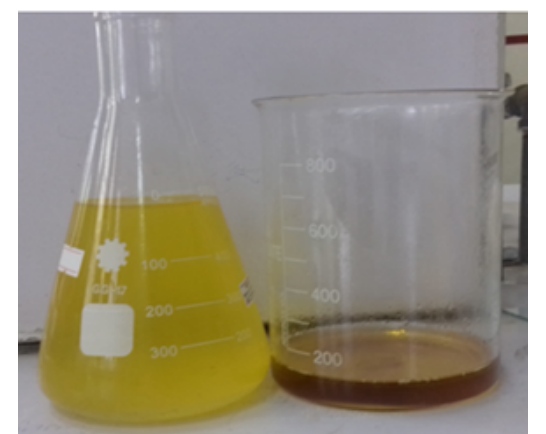

Right, biodiesel and glycerin after separation

Figure 2: Transesterification of $R$. communis seed oils (upper layer; biodiesel and bottom layer; glycerol).

The yield of the biodiesel was good enough (78\%) to substitute the regular diesel. The physicochemical properties of the biodiesel are given in Table 2 and the values are in close agreement with standards of ASTM. The standards also showed that the biodiesel need to be purified before it is used as a fuel or blended with petroleum-based diesel fuel. 


\section{Physicochemical Results}

The free fatty acid number of $R$. communis seed oils was determined to be $0.864 \%$ and the result was calculated from the following experimental values.

\section{Experimental results}

Volume used in Sample titration $=3.2 \mathrm{~mL}$

Volume used in Blank titration $=1.2 \mathrm{~mL}$

Volume of oil used $=1 \mathrm{~mL}$

Mass of Catalyst in $\mathrm{g} / \mathrm{L}=1.4 \mathrm{~g} / 1000 \mathrm{~mL}=1.4 \mathrm{~g} / \mathrm{L}$

FFA number $=\frac{(A-B) \times C}{D}$

Where $A=$ Volume used in sample/actual titration,

$B=$ Volume used in blank titration,

$\mathrm{C}=$ Mass of catalyst in $\mathrm{g} / \mathrm{L}$,

$\mathrm{D}=$ Volume of oil used.

$$
\begin{gathered}
\text { FFA number }=\frac{(3.2 \mathrm{~mL}-1.2 \mathrm{~mL}) \times 1.4 \mathrm{~g} / \mathrm{L}}{1 \mathrm{~mL}}=2.8 \mathrm{~g} / \mathrm{L} \\
\% F F A=\frac{2.8 \mathrm{~g}}{324 \mathrm{~g}} \times 100=0.864 \% .
\end{gathered}
$$

From Table 2 it can be seen that the density, viscosity, acid value, and water content of $R$. communis seed oil were found to be $0.887 \mathrm{~g} / \mathrm{mL}$, $35.5 \mathrm{~mm}^{2} \mathrm{~s}^{-1}, 26.78 \mathrm{mg} \mathrm{KOH} / \mathrm{g}$, and $2.8 \%$ respectively, which are in large amounts. Therefore, it is not advisable to use $R$. communis seed oil directly as a fuel, because these are essential properties that have to be monitored in seed/vegetable oil to meet the biodiesel standards.

Evaluation of physicochemical parameters is vital to investigate the features of the biodiesel and results were determined according to the standard procedures described by ASTM. Figure 3 showed that the biodiesel has better cetane number than the seed oils and the acid value, kinematic viscosity, iodine value and water content of the seed oils were found to be higher than the biodiesel. The acid value of the biodiesel was $0.35 \mathrm{mg} \mathrm{KOH} / \mathrm{g}$ (Table 2). According to the norms of the agency of national petroleum legislations, the established specification showed that the acid value is between 0.1 and 0.5 $\mathrm{mg} \mathrm{KOH} / \mathrm{g}$ and the obtained result was with in the interval of ASTM.

\section{GC-MS analysis}

A total of 10 different fatty acid methyl esters (Figure 5) were presented from the seed oil of the plant by GC-MS and include both saturated and unsaturated (Table 3). The Fatty acids were identified by means of their retention times, by comparison with the spectral data in the literature and mass spectral fragmentation patterns and by comparing their mass spectra with the NIST 2012 library of mass spectra. 9-Octadecenoic acid, 12hydroxy-, methyl ester, $[R-(Z)]$, 9,12octadecadienoic acid (Z, Z)-, methyl ester and 6octadecenoic acid, methyl ester, $(Z)$ - were the major compounds presented from the oil sample (Figure 4). 
Gebrehiwot H, Zelelew D. JOTCSA. 2022; 9(2): 339-354.

RESEARCH ARTICLE

Table 2: Physicochemical properties of castor oil and its biodiesel ( $\min =$ minimum; $\max =$ maximum; HSD=high speed diesel).

\begin{tabular}{|c|c|c|c|c|c|}
\hline Properties & Unit & Experimental results (oil) & $\begin{array}{c}\text { Experimental results } \\
\text { (biodiesel) }\end{array}$ & $\begin{array}{l}\text { ASTM standard } \\
\text { for biodiesel } \\
\text { (ASTM D 6751) }\end{array}$ & $\begin{array}{l}\text { ASTM standard } \\
\text { for Petrol diesel } \\
\text { (ASTM D975) }\end{array}$ \\
\hline Density & $\mathrm{g} / \mathrm{mL}$ & 0.887 & 0.8571 & $0.87-0.90$ & $0.95 \max$ \\
\hline Kinematic viscosity $\left(40^{\circ} \mathrm{C}\right)$ & $\mathrm{mm}^{2} \mathrm{~s}^{-1}$ & 35.5 & 5.42 & $1.9-6.0$ & $1.9-4.1$ \\
\hline Flash point & ${ }^{\circ} \mathrm{C}$ & - & 87 relative to HSD & $60-80$ & $150 \mathrm{~min}$ \\
\hline Acid value & $\mathrm{mg} \mathrm{KOH} / \mathrm{g}$ & 26.78 & 0.35 & $0.5 \max$ & - \\
\hline Water content & $\%$ & 2.8 & 0.8 & 0.05 & - \\
\hline Iodine value & I $2 \mathrm{~g} / 100 \mathrm{~g}$ & 110.8 & 108.6 & $120 \max$ & - \\
\hline Cetane number ( $\mathrm{CN})$ & - & 44 & 58.00 & $47 \min$ & $40 \mathrm{~min}$ \\
\hline
\end{tabular}

Table 3: Total Fatty acid methyl ester profile of $R$. communis seed oil.

\begin{tabular}{|c|c|c|c|c|c|}
\hline No & Retention time (tR) & Compound Name & Molecular formula & $\begin{array}{c}\begin{array}{c}\text { Relative } \\
\text { (Area) in \% }\end{array} \\
\end{array}$ & Abundance order \\
\hline 1 & 11.493 & Hexadecanoic acid-methyl ester & $\mathrm{C}_{17} \mathrm{H}_{34} \mathrm{O}_{2}$ & 1.08 & 4 \\
\hline 2 & 14.924 & 9,12-Octadecadienoic acid $(Z, Z)$ - methyl ester & $\mathrm{C}_{19} \mathrm{H}_{34} \mathrm{O}_{2}$ & 4.74 & 2 \\
\hline 3 & 15.073 & 6-Octadecenoic acid-methyl ester & $\mathrm{C}_{19} \mathrm{H}_{36} \mathrm{O}_{2}$ & 3.54 & 3 \\
\hline 4 & 15.184 & 9-Octadecenoic acid (Z)-methyl ester & $\mathrm{C}_{19} \mathrm{H}_{36} \mathrm{O}_{2}$ & 0.48 & 7 \\
\hline 5 & 15.618 & Methyl stearate & $\mathrm{C}_{19} \mathrm{H}_{38} \mathrm{O}_{2}$ & 1.07 & 5 \\
\hline 6 & 16.312 & 7-Hexadecenoic acid-methyl ester & $\mathrm{C}_{17} \mathrm{H}_{32} \mathrm{O}_{2}$ & 0.41 & 9 \\
\hline 7 & 16.905 & 9,12-Octadecadienoic acid $(Z, Z)$ & $\mathrm{C}_{18} \mathrm{H}_{32} \mathrm{O}_{2}$ & 0.05 & 10 \\
\hline 8 & 19.214 & 9-Octadecenoic acid, 12-hydroxy-methyl ester-[R-(Z)] & $\mathrm{C}_{19} \mathrm{H}_{36} \mathrm{O}_{3}$ & 87.60 & 1 \\
\hline 9 & 19.304 & cis-Methyl 11-eicosenoate & $\mathrm{C}_{21} \mathrm{H}_{40} \mathrm{O}_{2}$ & 0.57 & 6 \\
\hline 10 & 24.933 & $\begin{array}{c}\text { Octadecanoic acid, 9,10-dihydroxy-methyl ester } \\
\text { Saturated } \\
\text { Mono unsaturated }\end{array}$ & $\begin{array}{l}\mathrm{C}_{19} \mathrm{H}_{38} \mathrm{O}_{4} \\
\mathbf{2 . 5 9} \\
\mathbf{9 2 . 6 1}\end{array}$ & 0.43 & 8 \\
\hline & & Poly unsaturated & 4.80 & & \\
\hline
\end{tabular}




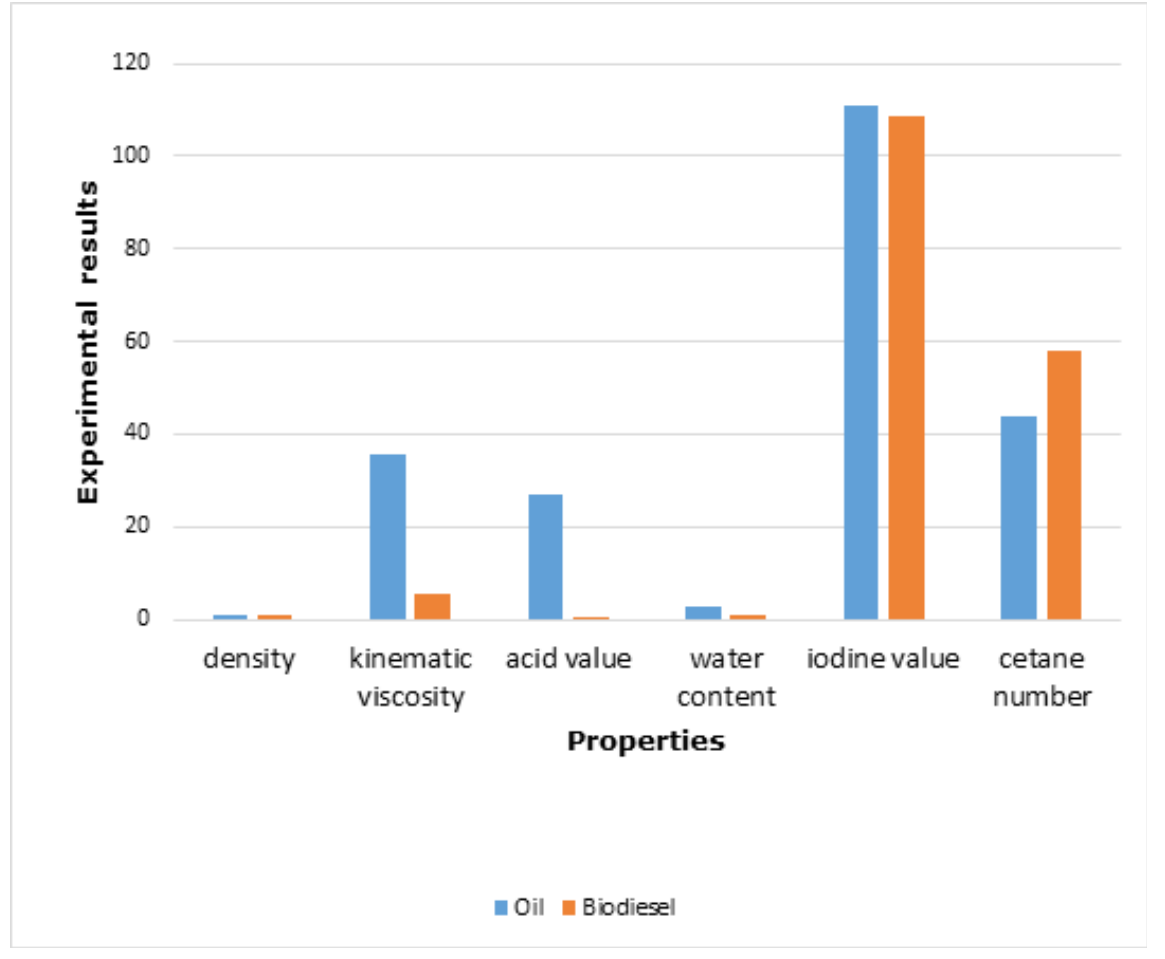

Figure 3: Comparison of the fuel properties of castor oil and its biodiesel.<smiles>CCCCCC[C@H](O)C/C=C/CCCCCCCC(=O)OC</smiles>

A

9-Octadecenoic acid, 12-hydroxy-, methyl ester, [R-(Z)]-<smiles>[B]C/C=C/C/C=C/CCCCCCC(=O)OC</smiles>

9,12-Octadecadienoic acid (Z, Z)-, methyl ester<smiles>CCCCCCCCCCC/C=C/CCCCC(=O)OC</smiles>

C

6-Octadecenoic acid, methyl ester, (Z)-

Figure 4: Proposed structures of the most abundant compounds from $R$. communis seed oil.

The total percentage of fatty acid methyl esters were $99.97 \%$ of which 9-octadecenoic acid, 12hydroxy-methyl ester-[R-(Z)] took the maximum percentage $(87.60 \%)$. All the values are represented as the relative percentage area from the sum of all identified peaks. The overall results of this analysis showed that the unsaturated fatty acids (UFA) make $97.31 \%$ of the compositions, whereby the monounsaturated fatty acids (MUFA) are $92.51 \%$, polyunsaturated fatty acids (PUFA) are $4.80 \%$; and the saturated fatty acids (SFA) are $2.59 \%$, as shown in Table 3. 


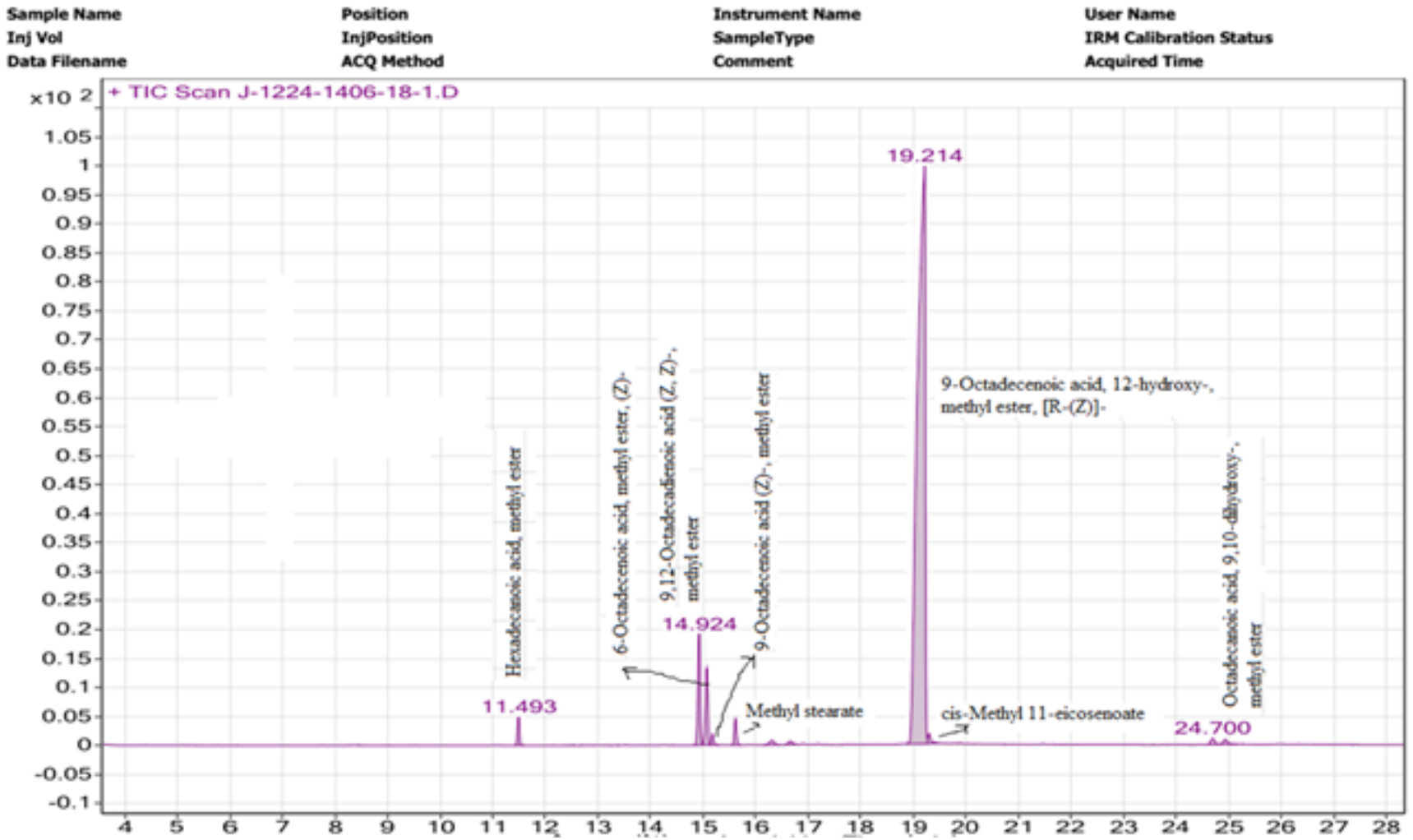

Figure 5: Gas chromatogram of $R$. communis seed oil with respect to its branded compounds.

The crude oil was evaluated by a means of gas chromatography and mass spectrometry (GC-MS) (Figures 5 and 6 ). The peaks were identified by the NIST 2012 library matching software. After evaluation, every single peak was matched with a single fatty acid methyl esters. The retention time (min) and position of the determined peaks are presented in Table 3. The GC-MS analysis was only towards the total fatty acid profile of the seed oil. As a result, other organic compounds were not identified in the sample.

The mass spectra of the seed oil of the plant displayed some important fatty acid methyl esters that have a significant contribution for the production of the biodiesel by transesterification process and the fragmentation pattern of the GC-MS results of the seed oil is shown in Figure 6.

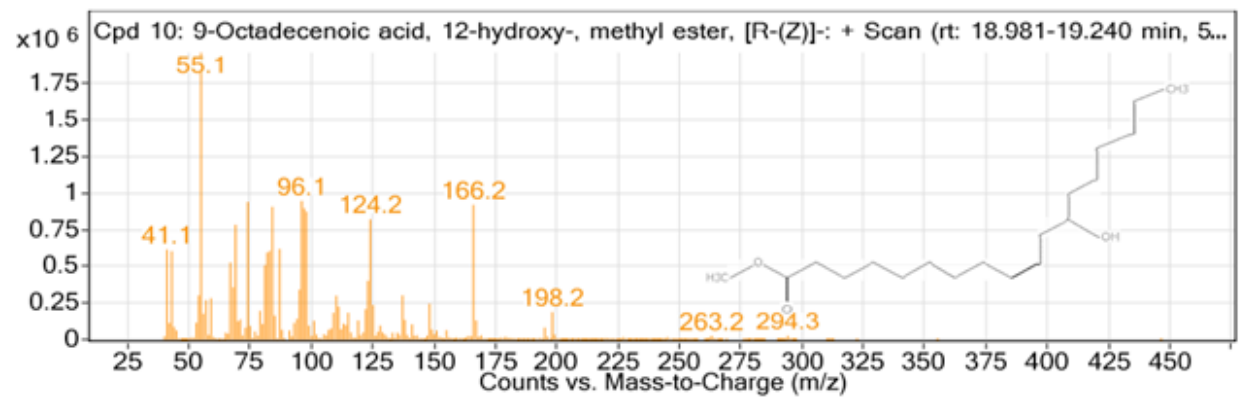

A) 9-Octadecenoic acid, 12-hydroxy-, methyl ester, [R-(Z)]- 


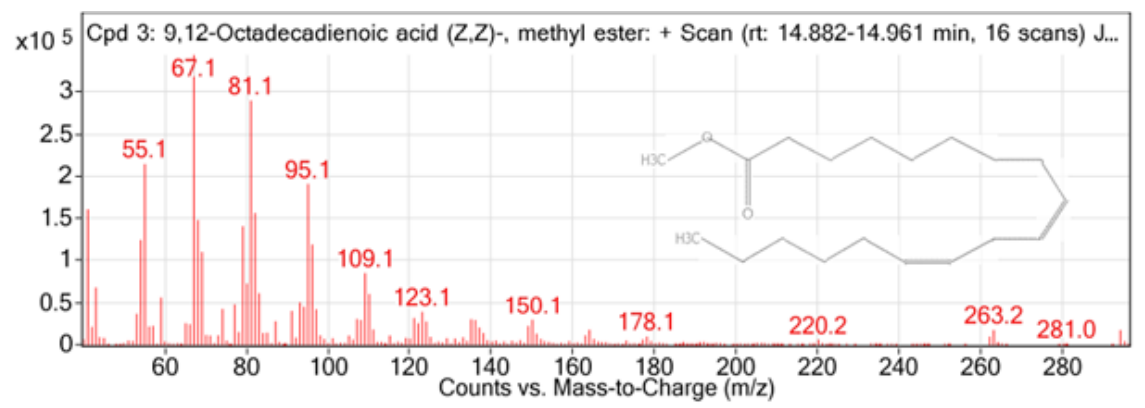

B) 9,12-Octadecadienoic acid $(Z, Z)-$, methyl ester

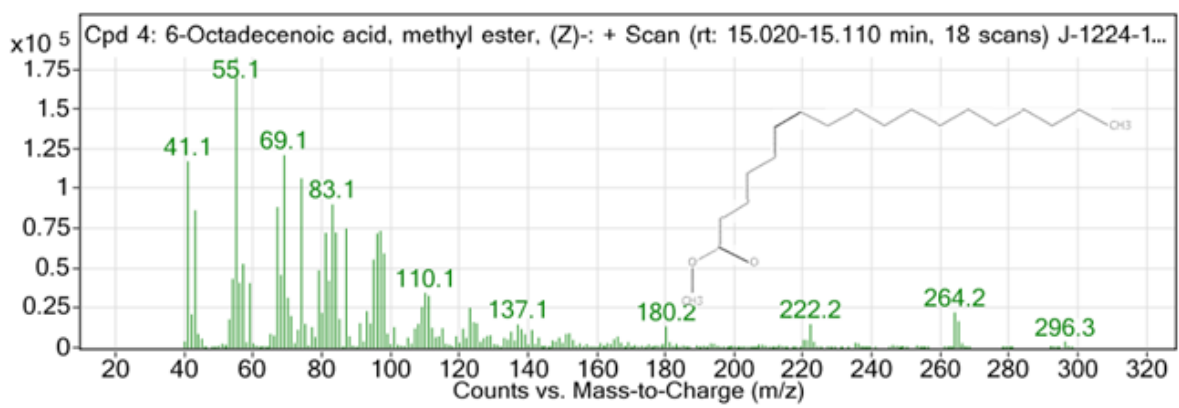

C) 6-Octadecenoic acid, methyl ester, (Z)

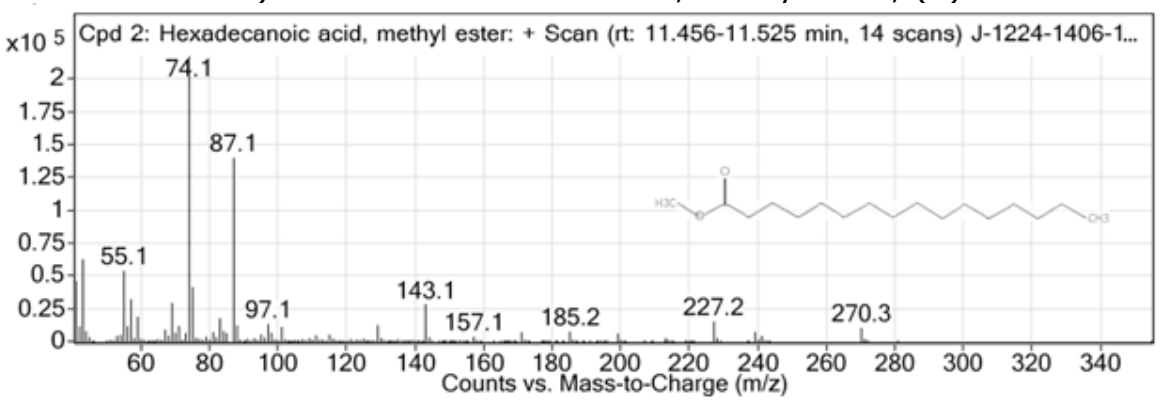

D) Hexadecanoic acid-methyl ester

Figure 6: Mass spectra of the major components of $R$. communis seed oil.

\section{Previous Reports}

In general our results agreed to what were reported by Torrentes-Espinoza et al., 2017 (41) who presented the physico-chemical parameters of $R$. communis biodiesel that showed smooth relationships with ours'. In addition, the biodiesel properties of the plant showed a good correlation with Awais, et al., 2020 (53) but with slight differences. The GC-MS results of the seed oils reported by Khan et al., 2021 (54) that contains mainly methyl stearate, 9-octadecenoic acid (Z)methyl ester, 9,12-octadecadienoic acid ( $Z, Z)$ methyl ester and cis- 11- eicosenoic acid-methyl ester (54) confirmed the presences of similar fatty acid methyl esters with the results of this study. Moreover, the properties of the biodiesel reported by Khan et al., 2021 (54) (density; $0.924 \mathrm{~g} / \mathrm{mL}$, cetane number; 54.53, acid number; $1.19 \mathrm{mg} \mathrm{KOH} / \mathrm{g}$ and water content; $0.31 \%$ ) were very close to our finding (density; $0.857 \mathrm{~g} / \mathrm{mL}$, cetane number;
58.00, acid number; $0.35 \mathrm{mgKOH} / \mathrm{g}$ and water content; $0.8 \%$ ).

The findings of this study are also in good agreement with the results obtained by Kiran and Prasad, 2017 (12), Zhang et al., 2015 (18), Yeboah et al., 2020 (36), Wara, 2015 (52), Anastasi et al., 2015 (55), Ramanjaneyulu et al., 2017 (56), Kondaiah et al., 2021 (57), Salihu et al., 2014 (58), Shombe et al., 2016 (59) and the seed oils were reported to possess an excellent energy substitute properties. The physicochemical results of the biodiesel showed that it can be used in any diesel engine (53). Many studies on the production of biodiesel from vegetable and seed oils were presented $(5,16,43,60-65)$ and the results are also in good agreement with the findings of this work.

In this study, the oil composition of the plant was reported to have a slight difference from some 
recently published reports. This is due to the fact that the chemical composition of oils rely on certain environmental factors such as geographical location, harvesting time, temperature, extraction methods and genetic variation of the plant.

\section{CONCLUSION}

In this work, extraction with n-hexane proved to be good, since a yield of $9.25 \%$ oil was obtained in relation to the mass of the seeds used in the process. Based on the results of the study, the oil properties are interesting and promising for several applications. Biodiesel was produced through the transesterification process with a yield of $78 \%$ in relation to the $R$. communis oil mass. The combustibility of $R$. communis biodiesel was found to be better than petroleum diesel. The produced biodiesel meets the requirements of international standards of ASTM. The analysis of results by GCMS strongly recommend that these crops are promising feed stocks for the production of biodiesel. So, R. communis seed oils could be used as future energy consumption replacing the current welfares of diesel and further studies are required to investigate its potential as feed stock for a new industrial products to intensify the future economic benefits of the plant.

\section{ACKNOWLEDGEMENTS}

The authors thanked to Wachemo University for the financial support and JIJE laboratory, Addis Ababa to cooperate in running the GC-MS results of the samples.

\section{CONFLICT OF INTEREST}

The authors declare that there is no conflict of interest for this manuscript.

\section{REFERENCES}

1. Tan X, Sudarsanam P, Tan J, Wang A, Zhang $\mathrm{H}$, $\mathrm{Li} H$, et al. Sulfonic acid-functionalized heterogeneous catalytic materials for efficient biodiesel production: a review. Journal of Environmental Chemical Engineering. 2021;9(1):104719. <DOI>.

2. Mubofu EB. Castor oil as a potential renewable resource for the production of functional materials. Sustainable Chemical Processes. 2016;4(1):1-12. <DOI>.

3. Hajlari SA, Najafi B, Ardabili SF. Castor oil, a source for biodiesel production and its impact on the diesel engine performance. Renewable Energy Focus. 2019;28:1-10. $\leq \mathrm{DOI}>$.

4. Keera S, El Sabagh S, Taman A. Castor oil biodiesel production and optimization. Egyptian
Journal of Petroleum. 2018;27(4):979-84. <DOI>.

5. Okechukwu R, Iwuchukwu A, Anuforo $\mathrm{H}$. Production and characterization of biodiesel from Ricinus communis seeds. Research Journal of Chemical Sciences, ISSN. 2015;2231:606X.

6. Elango RK, Sathiasivan K, Muthukumaran C, Thangavelu $V$, Rajesh $M$, Tamilarasan $K$. Transesterification of castor oil for biodiesel production: Process optimization and characterization. Microchemical Journal. 2019;145:1162-8. <DOI>.

7. Sánchez N, Encinar JM, Nogales S, González JF. Biodiesel production from castor oil by two-step catalytic transesterification: Optimization of the process and economic assessment. Catalysts. 2019;9(10):864. <DOI $>$.

8. Banerjee A, Varshney D, Kumar $S$, Chaudhary $\mathrm{P}$, Gupta V. Biodiesel production from castor oil: ANN modeling and kinetic parameter estimation. International Journal of Industrial Chemistry. 2017;8(3):253-62. <DOI>.

9. Hailegiorgis SM, Hasraff MA, Khan SN, Ayoub M. Methanolysis of castor oil and parametric optimization. Procedia engineering. 2016;148:54652. $\leq \mathrm{DOI}>$.

10. Pal A, Singh B, Mohan S. Waste Cooking Oil (WCO) Biodiesel Production Using Calcined Chalk as Heterogeneous Catalyst. Biofuels and Bioenergy (BICE2016): Springer; 2017. p. 1-13. $\leq U R L>$.

11. Kaur R, Bhaskar T. Potential of castor plant (Ricinus communis) for production of biofuels, chemicals, and value-added products. Waste biorefinery: Elsevier; 2020. p. 269-310. ISBN: 9780-12-818228-4.

12. Kiran BR, Prasad MNV. Ricinus communis L. (Castor bean), a potential multi-purpose environmental crop for improved and integrated phytoremediation. The EuroBiotech Journal. 2017;1(2):1-16.

13. Zhang A, Wang Q, He Y, Lai P, Miu Y, Xiao Z, editors. Preparation of Biodiesel Based on Alkaline Ionic Liquid [Bmim] OH Catalyzed Castor Oil. IOP Conference Series: Materials Science and Engineering; 2020: IOP Publishing. <DOI>.

14. Alwaseem $\mathrm{H}$, Donahue $\mathrm{CJ}$, Marincean $\mathrm{S}$. Catalytic transfer hydrogenation of castor oil. Journal of Chemical Education. 2014;91(4):575-8. <DOI $>$.

15. Dasari SR, Goud VV. Comparative extraction of castor seed oil using polar and non polar solvents. Int J Curr Eng Technol. 2013;1:121-3. 
16. Nakarmi A, Joshi S. A study on Castor Oil and its Conversion into Biodiesel by Transesterification Method. Nepal Journal of Science and Technology. 2014;15(1):45-52. <DOI>.

17. Satpathy $P$, Thosar A, Rajan AP. Green technology for glycerol waste from biodiesel plant. Int J Curr Microbiol App Sci. 2014;3:730-9.

18. Zhang $Q$, Sun $Y$, Zhi L, Zhang $Y$, Di Serio $M$. Properties of ethoxylated castor oil acid methyl esters prepared by ethoxylation over an alkaline catalyst. Journal of Surfactants and Detergents. 2015;18(2):365-70. <DOI>.

19. Gómez JJM, Saadaoui E, Cervantes E. Seed shape of castor bean (Ricinus communis L.) grown in different regions of Tunisia. Journal of Agriculture and Ecology Research International. 2016:1-11.

20. Velasco L, Fernández-Cuesta Á, PascualVillalobos MJ, Fernández-Martínez JM. Variability of seed quality traits in wild and semi-wild accessions of castor collected in Spain. Industrial Crops and Products. 2015;65:203-9. <DOI>.

21. Asmare M, Gabbiye N. Synthesis and characterization of biodiesel from castor bean as alternative fuel for diesel engine. American Journal of Energy Engineering. 2014;2(1):1-15.

22. Gebreegziabher Z, Mekonnen A, Ferede T, Kohlin G. Profitability of bioethanol production: the case of Ethiopia. Ethiopian Journal of Economics. 2017;26(1):101-22. $\leq$ URL $>$.

23. Bateni $\mathrm{H}$, Karimi $\mathrm{K}$. Biodiesel production from castor plant integrating ethanol production via a biorefinery approach. Chemical Engineering Research and Design. 2016;107:4-12. <DOI>.

24. Demirbas A, Bafail A, Ahmad W, Sheikh M. Biodiesel production from non-edible plant oils. Energy Exploration \& Exploitation. 2016;34(2):290318. <DOI>.

25. Hoekman SK, Broch A, Robbins C, Ceniceros E, Natarajan M. Review of biodiesel composition, properties, and specifications. Renewable and sustainable energy reviews. 2012;16(1):143-69. <DOI $>$.

26. Ijaz M, Bahtti KH, Anwar Z, Dogar UF, Irshad $M$. Production, optimization and quality assessment of biodiesel from Ricinus communis L. oil. Journal of Radiation Research and Applied Sciences. 2016;9(2):180-4. <DOI>.

27. Issariyakul T, Dalai AK. Biodiesel from vegetable oils. Renewable and Sustainable Energy Reviews. 2014;31:446-71. <DOI>.
28. Osorio-González CS, Gómez-Falcon $N$, Sandoval-Salas F, Saini R, Brar SK, Ramírez AA. Production of Biodiesel from Castor Oil: A Review. Energies. 2020;13(10):2467. <DOI>.

29. Sajjadi B, Raman AAA, Arandiyan H. A comprehensive review on properties of edible and non-edible vegetable oil-based biodiesel: Composition, specifications and prediction models. Renewable and Sustainable Energy Reviews. 2016;63:62-92. <DOI .

30. Fagnano $M$, Visconti D, Fiorentino N. Agronomic approaches for characterization, remediation, and monitoring of contaminated sites. Agronomy. 2020;10(9):1335. <DOI>.

31. Alam M, Rahman K. Biodiesel from mustard oil: a sustainable engine fuel substitute for Bangladesh. International Journal of Renewable Energy Development. 2013;2(3):141-9. <DOI>.

32. Devarajan Y, Munuswamy DB, Nagappan B, Pandian AK. Performance, combustion and emission analysis of mustard oil biodiesel and octanol blends in diesel engine. Heat and Mass Transfer. 2018;54(6):1803-11. <DOI>.

33. Sanjid A, Masjuki H, Kalam M, Abedin M, Rahman SA. Experimental investigation of mustard biodiesel blend properties, performance, exhaust emission and noise in an unmodified diesel engine. APCBEE procedia. 2014;10:149-53. <DOI .

34. Uyumaz A. Combustion, performance and emission characteristics of a DI diesel engine fueled with mustard oil biodiesel fuel blends at different engine loads. Fuel. 2018;212:256-67. <DOI>.

35. Mekhilef S, Siga S, Saidur R. A review on palm oil biodiesel as a source of renewable fuel. Renewable and Sustainable Energy Reviews. 2011;15(4):1937-49. <DOI>.

36. Yeboah A, Ying S, Lu J, Xie Y, AmoanimaaDede $H$, Boateng KGA, et al. Castor oil (Ricinus communis): a review on the chemical composition and physicochemical properties. Food Science and Technology. 2020. <DOI>.

37. Barabas I, Todoruţ A, Băldean D. Performance and emission characteristics of an CI engine fueled with diesel-biodiesel-bioethanol blends. Fuel. 2010;89(12):3827-32. <DOI>.

38. Chaudhari B, Patel M, Dharajiya D, Patel A, Thakur M. Oil Content and Fatty Acid Composition in Castor (Ricinus communis L.) Genotypes. International Journal of Agriculture, Environment and Biotechnology. 2021;14(3):319-24. 
39. Omotehinse $S$, Igboanugo A, Ikhuoria E, Ehigie C. Characterization of castor seed oil extracted from the seed species native to Edo State, Nigeria. Journal of Science and Technology Research. 2019;1(1):45-54.

40. Panhwar T, Mahesar SA, Mahesar AW, Kandhro AA, Talpur FN, Laghari $Z \mathrm{H}$, et al. Characteristics and composition of a high oil yielding castor variety from Pakistan. Journal of Oleo Science. 2016;65(6):471-6. <DOI $>$.

41. Torrentes-Espinoza G, Miranda B, VegaBaudrit J, Mata-Segreda JF. Castor oil (Ricinus communis) supercritical methanolysis. Energy. 2017; 140:426-35. <DOI >.

42. Yusuf A, Mamza $P$, Ahmed A, Agunwa U. Extraction and characterization of castor seed oil from wild Ricinus communis Linn. International Journal of Science, Environment and Technology. 2015;4(5): 1392-404.

43. Deshpande D, Urunkar Y, Thakare P. Production of biodiesel from castor oil using acid and base catalysts. Research Journal of Chemical Sciences, ISSN. 2012;2231:606X.

44. Ahmad M, Teong LK, Zafar M, Sultana $S$, Sadia $H$, Khan MA. Prospects and potential of green fuel from some non traditional seed oils used as biodiesel. Biodiesel-feedstocks, production and applications. 2012:104-26. ISBN: 978-953-510910-5.

45. Ahmad M, Ullah K, Khan M, Ali S, Zafar M, Sultana S. Quantitative and qualitative analysis of sesame oil biodiesel. Energy sources, part A: Recovery, utilization, and environmental effects. 2011;33(13):1239-49. <DOI>.

46. Jessinta S, Azhari H, Saiful N, Abdurahman $\mathrm{H}$. Impact of geographic variation on physicochemical properties of neem (Azadirachta indica) seed oil. International Journal of Pharmaceutical Sciences and Research. 2014;5(10):4406-13.

47. Saxena $\mathrm{P}$, Jawale $\mathrm{S}$, Joshipura $\mathrm{MH}$. A review on prediction of properties of biodiesel and blends of biodiesel. Procedia Engineering. 2013;51:395-402. $<$ DOI $>$.

48. Thangaraj B, Solomon PR. Scope of biodiesel from oils of woody plants: a review. Clean Energy. 2020;4(2):89-106. <DOI>.

49. Mishra VK, Goswami R. A review of production, properties and advantages of biodiesel. Biofuels. 2018;9(2):273-89. <DOI $>$.

50. Fu J. Flash points measurements and prediction of biofuels and biofuel blends with aromatic fluids. Fuel. 2019;241:892-900. <DOI>.

51. Yahya SI, Aghel B. Estimation of kinematic viscosity of biodiesel-diesel blends: Comparison among accuracy of intelligent and empirical paradigms. Renewable Energy. 2021;177:318-26. <DOI $>$.

52. Warra A. Physico-chemical and GC/MS analysis of castor bean (Ricinus communis L.) seed oil. Chem Mater Res. 2015;7(2):2224-3224.

53. Awais M, Musmar SeA, Kabir F, Batool I, Rasheed MA, Jamil $F$, et al. Biodiesel Production from Melia azedarach and Ricinus communis Oil by Transesterification Process. Catalysts. 2020;10(4):427. <DOI>.

54. Khan IU, Chen $\mathrm{H}$, Yan Z, Chen J. Extraction and Quality Evaluation of Biodiesel from Six Familiar Non-Edible Plants Seeds. Processes. 2021;9(5):840. $\leq$ DOI $>$.

55. Anastasi $U$, Sortino $O$, Cosentino $S$, Patanè C. Seed yield and oil quality of perennial castor bean in a Mediterranean environment. International Journal of Plant Production. 2015;9(1):99-116.

56. Ramanjaneyulu A, Anudradha G, Ramana MV, Reddy A, Gopal NM. Multifarious uses of castor (Ricinus communis L.). International Journal of Economic Plants. 2017;4(4):170-6. $\leq$ URL $>$.

57. Kondaiah A, Rao YS, Kamitkar ND, Ibrahim SJA, Chandradass J, Kannan T. Influence of blends of castor seed biodiesel and diesel on engine characteristics. Materials Today: Proceedings. 2021;45:7043-9. <DOI>.

58. Salihu B, Gana AK, Apuyor B. Castor oil plant (Ricinus communis L.): botany, ecology and uses. International Journal of Science and Research. $2014 ; 3(5): 1333-41$.

59. Shombe GB, Mubofu EB, Mlowe S, Revaprasadu N. Synthesis and characterization of castor oil and ricinoleic acid capped CdS nanoparticles using single source precursors. Materials Science in Semiconductor Processing. 2016;43:230-7. <DOI $>$.

60. Aydin K, Sarıbıyık OY, Özcanlı M, Serin H, Serin $S$. Biodiesel Production from Ricinus Communis Oil and Its Blends with Soybean Biodiesel. Strojniski Vestnik/Journal of Mechanical Engineering. 2010;56(12). $\leq U R L>$.

61. Dias J, Araújo J, Costa J, Alvim-Ferraz M, Almeida M. Biodiesel production from raw castor oil. Energy. 2013;53:58-66. <DOI>. 
62. Ismail S, Abu S, Rezaur R, Sinin H. Biodiesel production from castor oil and its application in diesel engine. ASEAN Journal on Science and Technology for Development. 2014;31(2):90-100.

63. Jamil MF, Uemura $\mathrm{Y}$, Kusakabe K, Ayodele $O B$, Osman N, Ab Majid NMN, et al. Transesterification of mixture of castor oil and sunflower oil in millichannel reactor: FAME yield and flow behaviour. Procedia engineering. 2016;148:378-84. <DOI>.
64. Magriotis ZM, Carvalho MZ, Priscila F, Alves FC, Resende RF, Saczk AA. Castor bean (Ricinus communis L.) presscake from biodiesel production: An efficient low cost adsorbent for removal of textile dyes. Journal of Environmental Chemical Engineering. 2014;2(3):1731-40. <DOI>.

65. Sattanathan R. Production of biodiesel from castor oil with its performance and emission test. Int J Sci Res. 2015;4(1):273-9. 
Hadush G, Demis Z. JOTCSA. 2022; 9(2): 339-354.

\section{RESEARCH ARTICLE}

